\title{
THE JUNE MEETING IN SEATTLE
}

The five hundred eighty-first meeting of the American Mathematical Society was held at the University of Washington in Seattle, Washington, on Tuesday, Wednesday, Thursday, and Friday, June 13-16, 1961. There were 447 registrants at this meeting, 238 of whom were members of the Society. This meeting was held in conjunction with meetings of the Institute of Mathematical Statistics, the American Statistical Association, the Biometric Society, the Institute of Management Sciences, the Mathematical Association of America, and the Society for Industrial and Applied Mathematics.

By invitation of the Committee to Select Hour Speakers for Far Western Sectional Meetings, and sponsored by the Society with the financial aid of the Air Force Office of Scientific Research, a Symposium on Convexity was held on Tuesday, Wednesday, and Thursday. The program committee for this symposium consisted of Professor V. L. Klee, Chairman, Professor David Gale, Professor Branko Grünbaum, and Dr. Merle Andrew. The chairmen of the six sessions of the Symposium were Professors H. S. M. Coxeter, A. S. Besicovitch, T. S. Motzkin, Vlastimil Pták, Mahlon Day, and Ky Fan. The following addresses were presented at these sessions: Problem on a circle, Professor A. S. Besicovitch, University of Pennsylvania, and Cambridge University; Various notions of convexity for functions defined on matrix spaces, Dr. Chandler Davis, American Mathematical Society, Providence, Rhode Island; The dual cone and Helly type theorems, Professor F. A. Valentine, University of California, Los Angeles; Helly's theorem and its relatives, Professor Ludwig Danzer, University of Washington and University of Munich; An upper bound for the number of equal nonoverlapping spheres that can touch another of the same size, Professor H. S. M. Coxeter, University of Toronto; Measures of asymmetry for convex sets, Professor Branko Grünbaum, University of Washington, and the Hebrew University, Jerusalem; Closedness under a set of linear combinations, Professor T. S. Motzkin, University of California, Los Angeles; Cyclic and neighborly polytopes, Professor David Gale, Brown University; Simplifications of linear programs, Dr. Alan Hoffman, General Electric Company, New York, N. Y.; Total positivity and convexity, Professor Samuel Karlin, The Hebrew University, Jerusalem, and Stanford University; Rotundity, Professor Mahlon Day, University of Illinois; Some results on fixedpoint and extreme-point properties of compact convex sets, Professor Ky Fan, Wayne State University; Some theorems on extreme points, 
Dr. Robert Phelps, University of California, Berkeley; Convex cones and spectral theory, Professor Helmut Schaefer, University of Michigan; Convexity and weak compactness, Professor Vlastimil Pták, Tulane University, and the Czechoslovakian Academy of Sciences; Nearsphericity theorems, Professor Aryeh Dvoretzky, The Hebrew University, Jerusalem; Semispaces and the topology of convexity, Professor Preston Hammer, University of Wisconsin; Topological classification of convex bodies, Professor Victor Klee, University of Washington. The Proceedings of the Convexity Symposium will be published by the Society.

By invitation of the Committee to Select Hour Speakers for Far Western Sectional Meetings, Professor T. M. Apostol of the California Institute of Technology addressed the Society on Friday. His talk was entitled Some lattice point problems in the theory of numbers. Professor R. D. James introduced Professor Apostol.

There were six sessions for contributed papers on Friday, with Professors M. G. Arsove, R. A. Beaumont, C. B. Bell, Jr., V. L. Klee, A. E. Livingston, and W. B. Woolf presiding. 